\title{
NOTAS GEOMORFOLOGICAS SOBRE LA LAGUNA DE SARIÑENA
}

\author{
POR \\ M. J. Ibiñez, F. Pellicer y M. T. Echeyerría \\ Departamento de Geografía General \\ Universidad de Zaragoza
}

\section{INTRODUCCION}

La laguna de Sariñena se integra como fenómeno geomorfológico dentro del endorreismo que caracteriza al sector central de la Depresión del Ebro, siendo la más importante del foco situado al norte de la Sierra de Alcubierre en la depresión presomontana de Sariñena. Esta se abre en los materiales poco resistentes que colmataron la fosa del Ebro, constituídos en este sector fundamentalmente por margas y niveles de areniscas, y localizados entre las alineaciones mesozoico-paleógenas de las sierras exteriores pirenaicas y las aristas calcáreas de Alcubierre. Así pues, la depresión de Sariñena es una depresión erosiva, remodelada en formas típicamente cuaternarias durante el último período geológico y drenada hacia el Ebro por los ríos Alcanadre y Flúmen, en cuyo interfluvio se ubica precisamente la laguna. La laguna de Sariñena no es el único vestigio de endorreismo en el área en que se emplaza, pero sí la más representativa tanto por su extensión como por su carácter de laguna permanente, puesto que las localidades próximas a la confluencia Alcanadre-Cinca, al pie de la sierra de Ontiñena (El Basal, Basalet y Basalet de Don Juan), tienen carácter temporal al igual que las menos interesantes de la Laguneta o las cercanas a Lanaja.

\section{Parámetros de la Laguna}

La laguna de Sariñena se localiza a un kilómetro al oeste dẹl pueblo que le da su nombre, a unos $280 \mathrm{~m}$. de altitud absoluta según las cotas del mapa topográfico nacional 1:50.000. Su planta ha variado ostensiblemente en los últimos veinte años, como consecuencia de un aumento de su superficie que prácticamente se ha duplicado, pasando de poco más de 100 has. a rebasar las

$$
-25-
$$


200 has., valores fluctuantes lógicamente dada la variación estacional de la laguna. Esto ha supuesto la ampliación del perímetro que de $4 \mathrm{kms}$. medibles como media en los fotogramas de 1956 ha pasado a ser de unos $8 \mathrm{kms}$. en los correspondientes a 1975. En cuanto a su planta el cambio más patente es el de haberse alargado marcadamente en dirección sur, pues si bien el aumento de superficie afecta a todas las márgenes de la laguna, como cabe esperar de una elevación del nivel del agua del orden de $1,80 \mathrm{~m}$., solamente el sector septentrional de la laguna circunscribe su perímetro anterior al actual aun habiendo retrocedido las orillas una media de $100-150 \mathrm{~m}$., mientras que hacia el sur la lámina de agua se ha extendido $1 \mathrm{~km}$. Este cambio en la forma de la planta se constata muy bien al comparar los valores de máxima longitud y máxima anchura en 1956 y 1975 , siendo de $1,43 \times 1,09 \mathrm{kms}$. y $2,33 \times 1,37 \mathrm{kms}$. respectivamente. Como consecuencia de la dirección principal de inundación, la orientación claramente NW-SE de la antigua laguna tiende a ser en la actualidad dominantemente N-S, presentando una acusada concavidad en la margen occidental.

\section{El origeN de la lagtia}

El proceso morfogenético de la laguna de Sariñena, aunque presenta unos rasgos peculiares en función del contexto en que se inscribe, participa de las características comunes que han condicionado la aparición del endorreismo cuaternario general a la depresión del Ebro, y que se traduce en la multiplicidad de lagunas, estancas, balsas y charcas que salpican el paisaje estepario del Ebro y que se agrupan en la parte aragonesa de la depresión en cinco grandes conjuntos: Campo de Tarazona-Borja, Tierra de Belchite y tierras del Bajo Aragón, en el sector meridional, y Cinco Villas y Monegros al norte del eje del Ebro. En el extremo septentrional del foco de Monegros se sitúa la laguna de Sariñena.

\section{a) Un marco topográfico-estructural y climático favorable al endorreismo}

Las características comunes a las que nos referíamos, y de las cuales participa Sariñena, han sido tratadas en trabajos anteriores (D \TI C CEREC.EDA, 1942; Iв ́x́̃E, 1975), pudiendo resumirse a tres los factores condicionantes principales; el topográfico, el litológico y el climático, factores que al converger determinan el estancamiento de las aguas y por consiguiente la aparición de lagunas.

El primero de los factores interviene favorablemente en la génesis de lagunas cuando la horizontalidad topográfica domina en el paisaje, hecho que queda reforzado por la horizontalidad estructural de los materiales; de manera que la ausencia de pendientes topográfico-estructurales frena la escorrentía de las aguas superficiales, con la consiguiente imposibilidad de excavación de cauces y el establecimiento de una red hidrográfica eficaz y autóctona. Se produce así un encharcamiento del agua de lluvia en láminas 
superficiales más o menos discontinuas. Pero para que este encharcamiento sea efectivo se requiere además la impermeabilidad de las rocas, de forma que la pérdida de aguas superficiales por infiltración sea nula o mínima, pues de lo contrario el proceso de formación de lagunas o charcas queda bloqueado. En este sentido el factor litológico es decisivo en la génesis de los focos endorréicos.

Finalmente, el clima interviene también muy directamente en la aparición y pervivencia del fenómeno que tratamos, fundamentalmente a través de la relación temperatura-precipitación y de los valores de evapotranspiración. La escasez de precipitaciones anuales y las altas temperaturas estivales quedan reforzadas por una elevada evaporación, prácticamente el único medio natural de salida de las aguas estancadas; evaporación activada si converge la acción directa de un viento seco que renueve de forma casi continua un aire no saturado y con capacidad de absorver el agua de superficie. Todo lo cual se traduce en un déficit hídrico muy acusado, sobre todo durante el verano, que explica la escasez de agua sobrante para el arroyamiento superficial.

El sector de la laguna de Sariñena se ajusta perfectamente a los condicionantes generales descritos. Desde el punto de vista climático Sariñena, con una precipitación anual del orden de los $387 \mathrm{~mm}$. y una temperatura media de $14,7^{\circ}$, temperatura que en los meses estivales alcanza los $24,7^{\circ}$, se caracteriza por poseer un clima semiárido que se traduce en los índices de Thorvthuate y de De Martonne cuyos valores son de 60,3 y 11,8 respectivamente, y que permiten incluir a Sariñena dentro de las áreas de más marcada sequedad de la depresión del Ebro, con un déficit hídrico anual de $588 \mathrm{~mm}$. y que sólo alcanza valores de 0 en los meses de diciembre a marzo. Este carácter semiárido queda reflejado también en el diagrama de termohietas de Wilson (Fig. 1), en el que destaca la escasa variación pluviométrica intermensual, acentuándose la aridez sin embargo durante los meses estivales en función de los altos valores térmicos.

En cuanto a los factores de orden topográfico y litológico, ya hemos apuntado anteriormente que la laguna de Sariñena se halla instalada en una depresión presomontana excavada en materiales del terciario superior y en la que predominan las superficies planas o suavemente inclinadas. Los materiales terciarios que forman el sustrato litológico fueron sedimentados en régimen endorréico tras el paroxismo alpino, por lo que aparecen prácticamente horizontales o a lo sumo ligeramente deformados en amplios pliegues cuyos valores de buzamiento rara vez superan los 2-30. La misma laguna se ubica en el flanco sur, próxima a la charnela, de un pliegue anticlinal de dirección noroeste-sureste, considerado como de orden menor y cuyas pendientes estructurales son inferiores a los 2. ${ }^{\circ}$ (QUIRANTES, 1978). Este terciario subhorizontal se identifica en Sariñena con un Mioceno (aquitaniense-rindoboniense inferior) correspondiente a la denominada "formación Sariñena" (QuiRANTES, 1978), de facies detrítica en la que alternan margas con niveles más o menos discontinuos de areniscas, siendo las primeras dominantes en. el área en que se localiza la laguna, a la que sirven de basamento impermeable.

Estos materiales terciarios no afloran sin embargo de manera continua, sino solamente en los sectores sobreexcavados o erosionados por la red fluvial. 


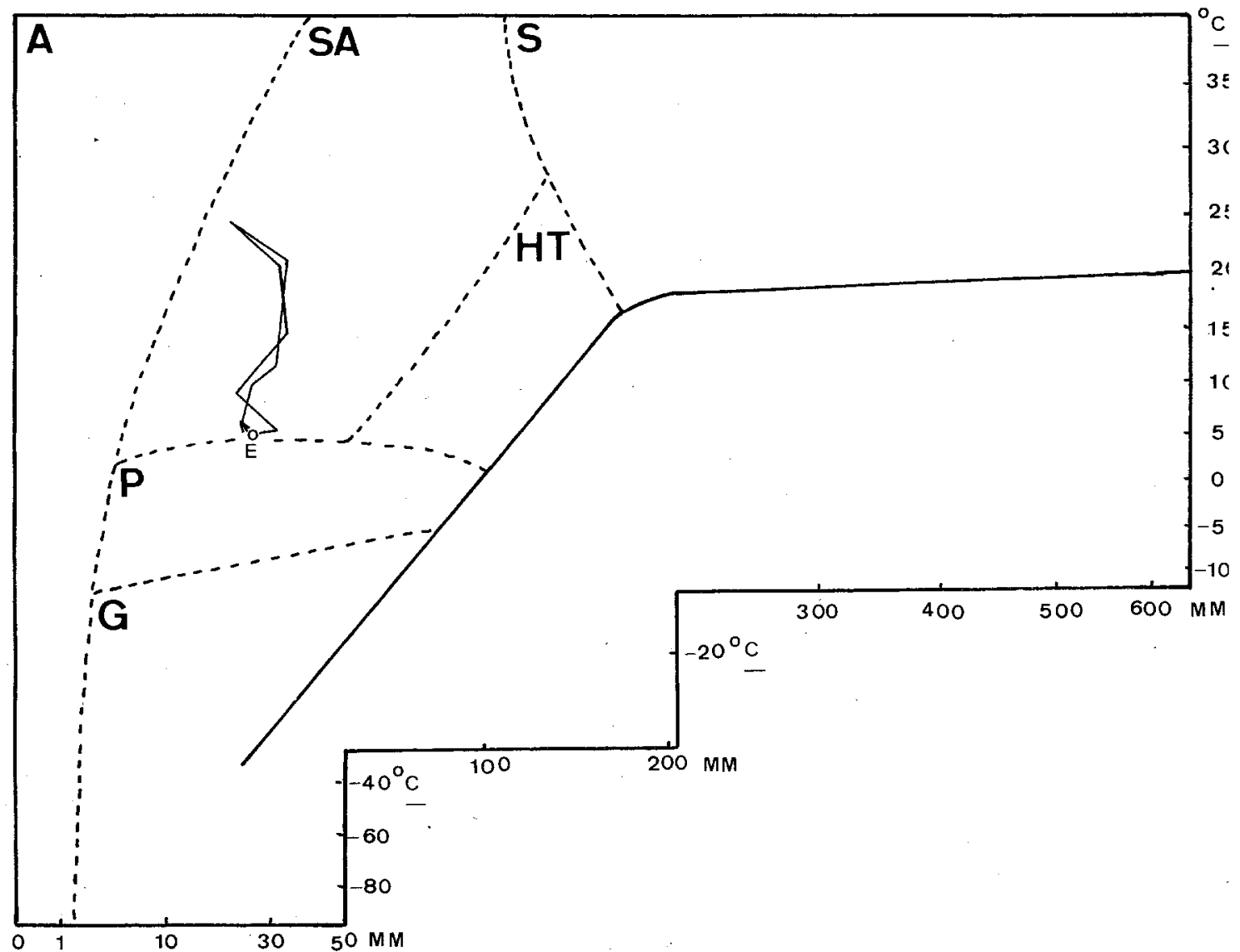

Fig. 1.-Sistema Morfoclimático de la estación de Sariñena 
Efectivamente, un manto detrítico cuaternario recubre el sustrato margoareniscoso con carácter de nivel de piedemonte y con una suave pendiente cuyo valor oscila entre 0,27 y $0,50 \%$. La potencia de este varía de 3 metros en el noroeste de la laguna (margen izquierda del Flúmen) a 1-2 metros al norte de la Estación (margen derecha del Alcanadre) o en las proximidades de Albalatillo, alcanzando de 4 a 5 metros al norte de Las Ramblas. Se trata pues de un depósito acumulado con desigual potencia sobre el basamento terciario con el que contacta a través de una superficie irregular.

Las características de este nivel cuaternario permiten su identificación con un nivel aluvial, T III, correspondiente a una terraza de confluencia Alcanadre-Flúmen. Los depósitos ligados a uno y otro río son muy semejantes, existiendo un total predominio de elementos groseros, con clara heterometría aunque se observa un alto porcentaje de elementos de talla entre 5 y $10 \mathrm{~cm}$., siendo poco frecuentes los lechos de material arenoso. Petrográficamente los cantos más abundantes son de caliza mesozóica o eocena que en conjunto llegan a suponer un $80 \%$, repartiéndose el porcentaje restante los cantos de arenisca, cuarcita y otras litologías menos representativas. Los detritus presentan una cierta ordenación, dominando la estratificación horizontal y disponiéndose individualmente los cantos con inclinación al norte, todo lo cual confirma un transporte y sedimentación en medio acuático poco tumultuoso y con capacidad selectiva. Las observaciones morfométricas del depósito, realizadas exclusivamente sobre cantos calcáreos de 6-8 cm. como elementos más significativos, traducen así mismo un medio fluvial, con índices de desgaste de 383 para el Alcanadre y 380 para el Flúmen, e índices de aplanamiento de 2,32 para el Alcanadre y 1,87 para el Flúmen (Figura 2). El depósito aparece frecuentemente cementado por carbonato cálcico.

Junto a esta facies típicamente fluvial hemos hallado en el mismo nivel interfluvial de la laguna otra facies detrítica, en general fuertemente encostrada (Foto 1), constituída por elementos de talla entre 2 y $6 \mathrm{~cm}$., predominantemente calcáreos, pero que a diferencia de los componentes de la facies normal anteriormente descrita son subangulosos, aunque pueden aparecer también elementos rodados. Otro aspecto diferenciador viene dado por el hecho de que los elementos integrantes de esta facies son muy aplanados. Así pues, respecto de la facies normal en ésta disminuye el valor del índice de desgaste que oscila entre 176 y 243 , y aumenta el valor del índice de aplanamiento que se sitúa entre 3,08 y 4,17. Por último cabe destacar las superficies de corrosión y disolución que presentan los cantos de esta facies secundaria. El depósito se encuentra espacialmente disperso en el nivel fundamental de la laguna, existiendo testigos de él en una franja intermedia al Alcanadre-Flúmen, más próxima a éste, con dirección N.NWS.SE entre el oeste de la laguna y el norte de Las Ramblas, bien fosilizando la facies normal de la terraza (Foto 2), como en el último de los puntos citados, bien sobre los materiales terciarios, como en El Puyalón o en los cerros que se elevan marginando la laguna por su orilla occidental y en los que genera una pequeña cornisa de $50-60 \mathrm{~cm}$. de patencia.

Aunque el aspecto de este depósito es sensiblemente diferente al de la facies normal, lo interpretamos también como una acumulación aluvial correspondiente bien a un horizonte superior sometido a una meteorización 


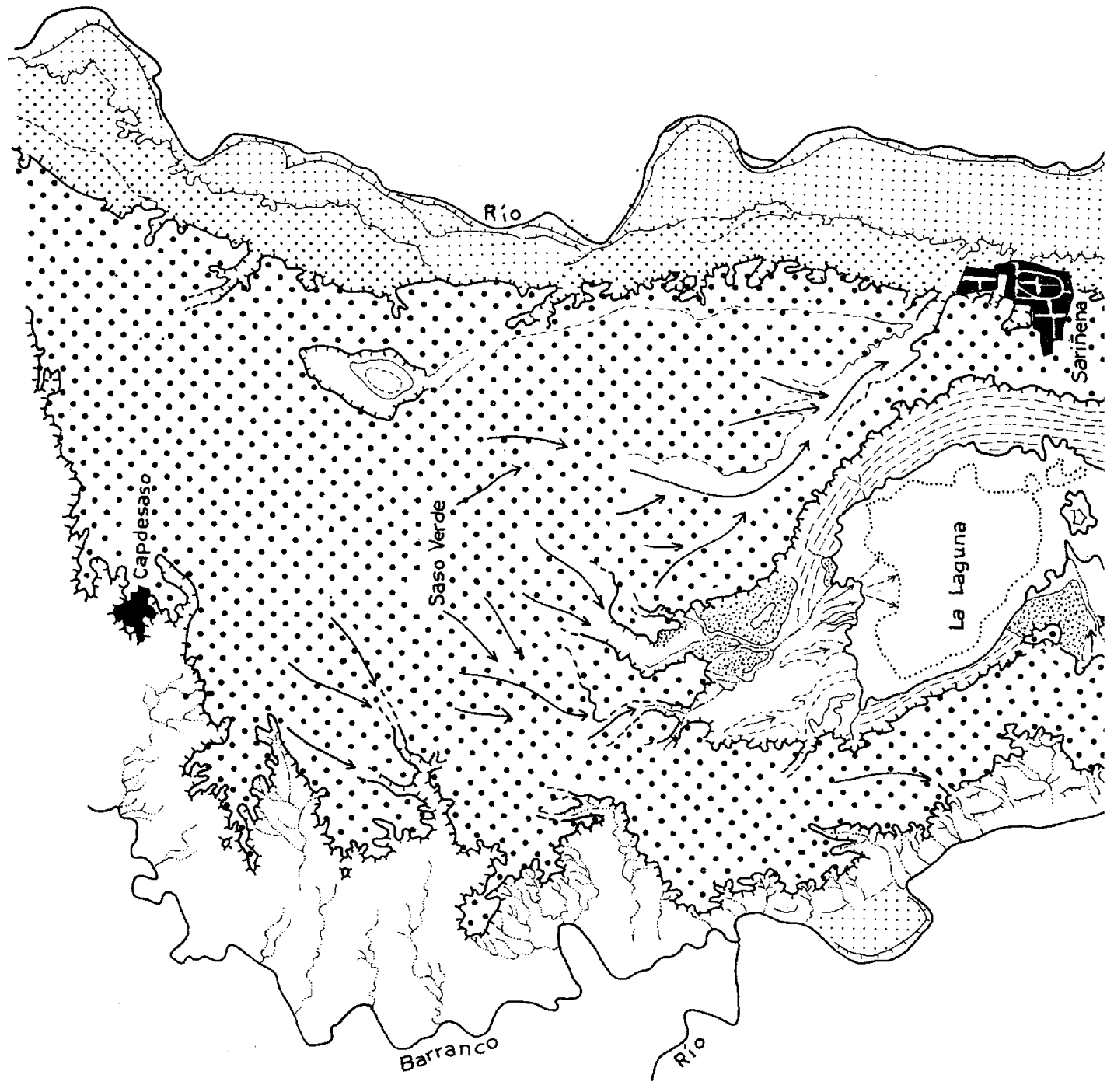



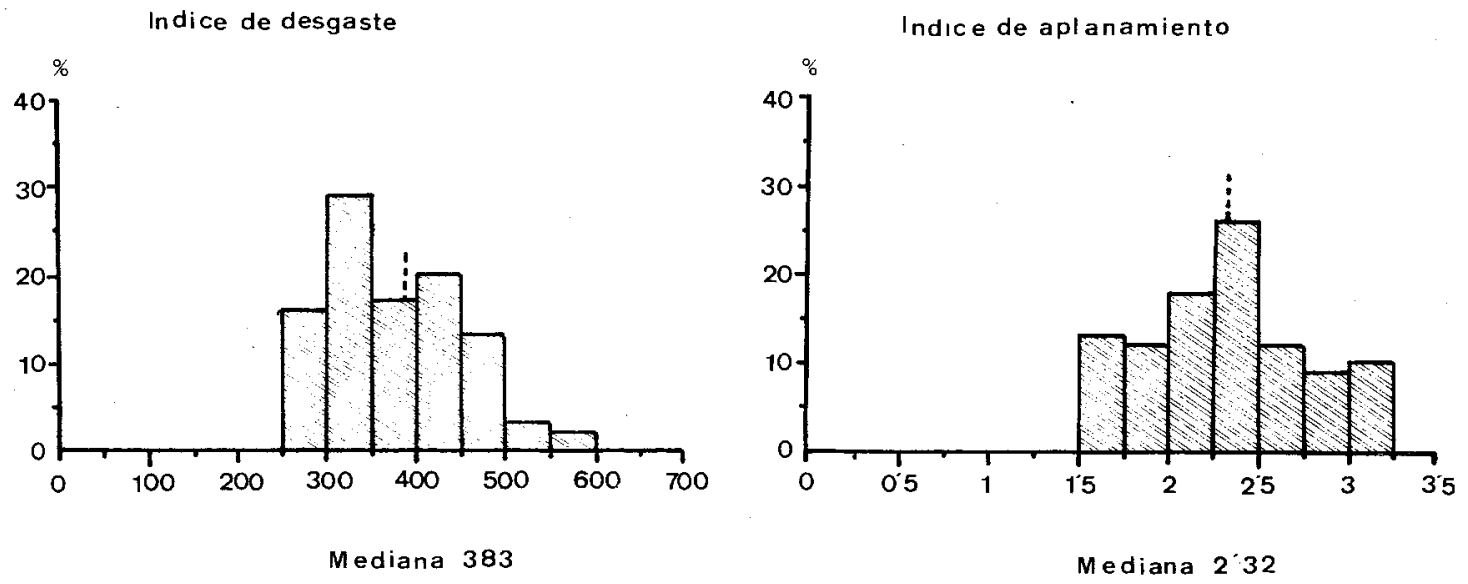

Fig. 2-A.-Nivel aluvial T III - Río Alcanadre.

Indice de desgaste

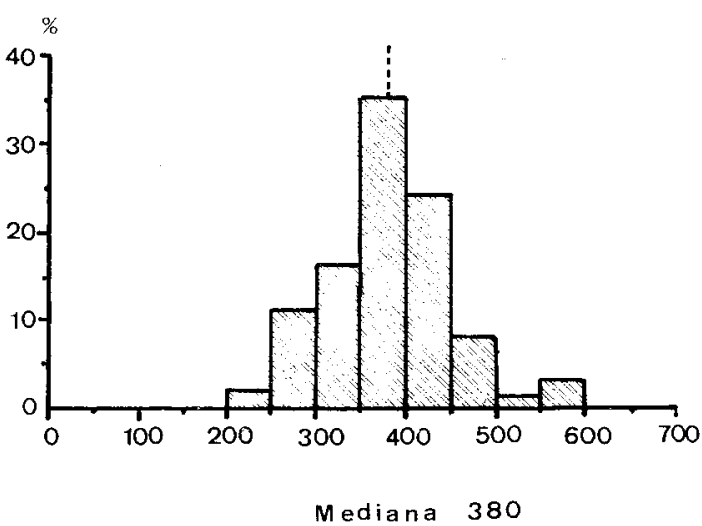

Indice de aplanamiento

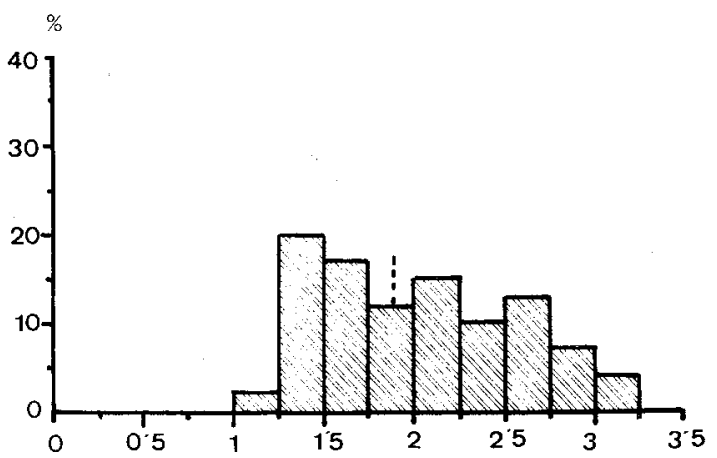

Mediana 1.87

Fig. 2-B. - Nivel aluvial T III - Río Flumen. 
intensa, avalada por los fenómenos de corrosión y disolución a que anteriormente aludíamos, bien a un depósito retomado de un nivel aluvial más antiguo. Cualquiera de las dos hipótesis explicaría el carácter atípico de la facies. Cronológicamente se correspondería con la fase final de deposición de la T III, con la cual se relaciona lateralmente o por fosilización. Esta discontinuidad de facies en el nivel cuaternario interfluvial es interesante para explicar la excavación de la cubeta en la que se aloja la laguna.

\section{b) La excavación de la cubeta}

Dados los condicionantes básicos para la instalación de un centro endorréico, el problema fundamental es conocer los procesos que han podido intervenir en la excavación de las cubetas. La solución no siempre es fácil y hay que partir de una serie de hechos observados para aproximarnos a ella.

La laguna de Sariñena está alojada en una cubeta (Foto 3) de planta alargada, con dimensiones de $3,5 \times 1,5 \mathrm{kms}$. aproximadamente, y se encaja en una superficie topográfica subhorizontal con ligera pendiente generalizada al sur e identificada con el mencionado nivel aluvial. Dos hechos significativos referidos a este nivel aluvial son: por una parte que dicho nivel presenta una heterogeneidad de facies detríticas que supone una discontinuidad en superficie favorable a los procesos de erosión diferencial; por otra parte el hecho de que la cubierta aluvial posea diferencias de potencia que van de menos de medio metro a más de cuatro, lo que conduce a pensar que dicha cubierta se acuña lateralmente en determinadas direcciones, e incluso cabe plantear la posibilidad de que algunos sectores del plano topográfico original careciesen de ella aflorando pues en superficie los materiales terciarios. En uno y otro caso se crean líneas o pequeñas áreas de debilidad frente a la erosión, a partir de las cuales se inicia el desmantelamiento del nivel superficial.

Una vez esbozada la excavación de la cubeta su ampliación pudo producirse con relativa facilidad teniendo en cuenta las características litológicas del sustrato. En nuestra opinión los procesos hidroeólicos han sido determinantes al actuar sobre unos materiales margosos poco resistentes, y cuya evolución condicionaría el retroceso de la cornisa aluvial suprayacente y en consecuencia el ensanchamiento de la caja de la laguna. La hipótesis hidroeólica como explicativa de la génesis de la cubeta, y aplicada a otros focos endorréicos de la depresión del Ebro, se fundamenta en una excavación progresiva a partir de la fase inicial y con sucesión temporal de los siguientes procesos: durante los momentos de lluvia se produce un encharcamiento de la superficie, con la consiguiente alteración y disgregación de los materiales humectados; en las fases secas una deflacción eólica, actuando sobre los detritus generados en la fase anterior y afectando directamente a las margas, provocaría el "barrido" del fondo de la cubeta. En ésta las aguas, estacionalmente primero y con carácter permanente después, quedan estancadas por ausencia de eferentes que las evacuen, por lo que, haciendo omisión de la manipulación antrópica, el nivel del agua es función exclusivamente de los ciclos de precipitación y evaporación, con los cuales se 
relaciona también la precipitación de sales disueltas que llegan a formar costras blanquecinas (Foto 4) orlando el fondo de la cubeta en los periodos de aguas bajas.

El origen hidroeólico de la cubeta de Sariñena es aceptable tanto por el tipo de materiales poco resistentes en los que se encaja, como por la orientación que presenta el eje de máxima elongación y que es NW-SE, tendiendo a N.NW-S.SE, coincidente a grandes rasgos con la dirección de vientos dominantes en este sector, lo que permite aceptar al viento como agente fundamental de la erosión. Por otra parte, no hemos hallado ningún dato sobre el que basar claramente una hipótesis tectónica explicativa de la génesis de la cubeta, salvo señalar la coincidencia entre la dirección de ésta y la de las líneas tectónicas generales en este sector de la depresión del Ebro. En el foco de Bujaraloz-Sástago, situado a $40 \mathrm{kms}$. al sur de Sariñena, las lagunas endorréicas se alojan en cubetas alargadas en dirección W.NW-E.SE, relacionadas con una red de diaclasas orientadas en la misma dirección y afectando a los bancos de caliza de la plataforma terciaria (Quirantes, 1965). Sin embargo, el contexto morfolitológico en que se emplaza la laguna de Sariñena difiere de aquel, y la ausencia de niveles-guía resistentes y especialmente continuos nos impide poder referirnos a un fenómeno similar o a cualquier otro de tipo tectónico condicionando directa y primordialmente la excavación de la cubeta.

\section{b) Cronología de la laguna}

Aunque carecemos de datos que permitan establecer una conología absoluta referida al momento en que se origina la laguna de Sariñena, un intento de datación puede realizarse a través de su conexión con los niveles cuaternarios. Ya hemos apuntado que la cubeta se abrió a partir de un nivel de terraza, si bien la base y los taludes de aquélla se corresponden con el terciario infrayacente. Dicha terraza fluvial se identifica con la superficie aluvial que hemos considerado como T III, tanto por su altitud relativa sobre los actuales cauces de los ríos Alcanadre y Flúmen, que es de $35-50 \mathrm{~m}$., desnivel normal a la $T$ III en la 'mayor parte de los componentes de la red afluente al Ebro, como por el recuento de niveles intermedios que se superponen, y que si bien en el Flúmen son prácticamente inexistentes en su margen izquierda en el sector de Sariñena, en el Alcanadre están bien representados, aunque muy retocados por el hombre, pudiéndose reconocer además del lecho de inundación un nivel inferior a $T \mathbf{I}$, a una altitud media absoluta de $265 \mathrm{~m}$., un nivel intermedio, en el que se ubira gran parte de Sariñena, a unos $270-280 \mathrm{~m}$. y que sectorialmente puede aparecer desdoblado, y finalmente el nivel alto o T III, en el que se encaja la laguna, a unos 285$300 \mathrm{~m}$. y que como el anterior presenta localmente un desdoblamiento.

La datación relativa atribuida al nivel alto o $T$ III es de cuaternario medio, por lo que el proceso genético imicial de la cubeta tiene que ser posterior a ese momento, y su desarrollo pudo producirse a lo largo de la fase transicional cuaternario medio-cuaternario reciente así como durante este último. El endorreismo actual de Sariñena es pues relativamente moderno a 
escala geológica, lo que coincide con la generalidad de lo observado en la depresión del Ebro. En apoyo de esta hipótesis está también el emplazamiento concreto de la laguna en una cuña aluvial interfluvial, colgada a unos $30 \mathrm{~m}$. sobre los ríos Alcanadre y Flúmen de los que linealmente solo dista 2 y $1 \mathrm{~km}$. respectivamente, habiendo quedado reducidas las cumbres interfluviales que la separa de dichos ríos a unos 500 metros en algunos sectores (Figura 3). El hecho de que ninguno de los dos cursos fluviales, a través de barrancos afluentes, haya capturado la laguna estableciendo su drenaje es indudablemente un dato a favor de la relativa juventud de la laguna de Sarinena.

\section{Morfología de las márgenes de la laguna}

La cubeta que aloja la laguna presenta como dominante una morfología en vertientes modeladas entre el techo del nivel aluvial y la lámina de agua. Sin embargo los valores de pendiente de las márgenes difieren, oscilando entre un $2,1 \%$ y un $17,1 \%$; oscilación que traduce por una parte la ausencia de simetría en los perfiles de la caja de la laguna, y por otra la diferente morfología de unos sectores a otros. Los valores más débiles corresponden a las márgenes norte y sur, mientras que la oriental y occidental, aunque más abruptas, presentan entre sí un claro contraste patente sobre todo en la mitad meridional:

Vertiente

Norte......

Oeste $\ldots \ldots \ldots$

Sur $\ldots . . . . .$.

Este.........
Noroeste ..............

Noroeste ...............

Mitad septentrional .......

Mitad meridional .........

Mitad septentrional $\ldots \ldots \ldots$

Mitad meridional ..........
Valores de pendiente (\%)

$$
\begin{gathered}
7,2 \\
2,1 \cdot 2,8 \\
5,2-12,0 \\
15,7 \cdot 12,1-17,1 \\
4,0-3,7 \\
11,1-10,0 \\
2,1-2,8
\end{gathered}
$$

En las márgenes de la laguna pueden diferenciarse en conjunto las siguientes tipologías: vertientes con cornisa, vertiente con bancales antrópicos, orillas de tipo delta y orillas anfibias o pantanosas. Los dos primeros tipos se corresponden en general con las márgenes escarpadas, si bien la remodelación del talud en bancales aparece también en las márgenes tendidas del sureste y sur; los dos últimos tipos coinciden con las márgenes de menor pendiente.

Las más representativas de las vertientes con cornisa se localizan en la margen occidental de la laguna, concretamente en su sector meridional, en los cerros coronados por la facies detrítica subangulosa muy cementada. Se trata de vertientes típicas con cornisa y talud, este último modelado en las margas poco resistentes que imponen la concavidad basal a la vertiente, en la que apuntan algunos lechos poco potentes de areniscas. Estas vertientes dan los valores máximos de pendiente en las márgenes de la laguna, entre un 12! un 


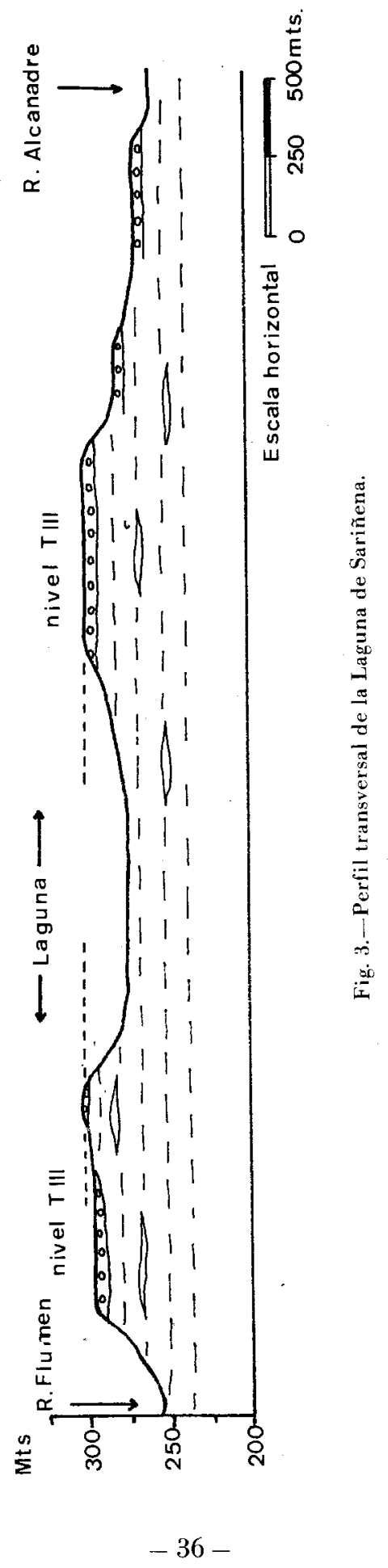


$17 \%$, valor que aumenta si se considera solo la parte somital. El talud, que parcialmente puede hallarse retocado antrópicamente en bancales aunque abandonado en la actualidad, se encuentra en fase regresiva, cubierto de forma dispersa por una vegetación rala esteparia incapaz de proteger, y en consecuencia desestabilizado y sometido a una intensa erosión de tipo aerolar o en microcauces que abarrancan los materiales terciarios. Sobre este talud la cornisa, poco patente, evoluciona fundamentalmente por gravedad.

Las vertientes con bancales antrópicos son las dominantes en todas las márgenes de la laguna, si bien solo se mantienen funcionales en la oriental y suroriental. En este tipo la cornisa coincide con el nivel detrítico aluvial, más nítida en el sector septentrional del borde este y bastante modificada y evolucionada por acción del hombre en el resto, lo que se traduce en unos valores globales de pendiente más acusados en el primero de los casos.

Respecto a las orillas en delta existe un solo caso digno de mención, localizado en la margen norte de a laguna. Está en relación con el único afluente importante, el barranco de Saso Verde, el cual ha desmantelado el nivel de gravas de cumbre y excava su cauce en las margas con lechos de areniseas del sustrato. Los aportes terrígenos del barranco avanzan sobre la laguna en pequeño delta, coincidente con la convexidad que presenta la planta en este sector.

Finalmente caben citarse las orillas transicionales anfibias o pantanosas. Aunque gran parte de la orla marginal de la laguna podría incluirse en este tipo debido a la oscilación estacional del nivel de las aguas, nos referimos espacialmente a la margen meridional, la más recientemente inundada y que por su menor profundidad es la más representativa de este tipo.

De los diferentes tipos de vertientes las más estables, a pesar de la continụa intervención antrópica, son las que poseen bancales funcionales. Sin embargo, en cualquiera de ellas los procesos morfogenéticos naturales se hallan frenados y los mecanismos erosivos acelerados por la acción del hombre.

\section{Algunos aspectos hidrológicos}

No abordaremos la hidrología de la laguna en sí, sino solamente ciertos aspectos hidrológicos que caracterizan el cuadro morfológico de la misma.

El arroyamiento superficial que se produce sobre el nivel topográfico en que se inscribe la laguna es fundamentalmente un arroyamiento no impreso, y del que solo es excepción el citado barranco de Saso Verde, el cual canaliza hacia la laguna las arroyadas superficiales que recibe del paraje de Saso Verde. Fuera de este caso, las aguas, que fluyen en principio por áreas ligeramente deprimidas y carentes de límites concretos (el mismo sector de Saso Verde, sector suroeste de la Estación, sector de El Puyalón o del Saso de Albalatillo), tienden a encauzarse en vallonadas poco marcadas para en unos casos desaparecer en los niveles inferiores del Alcanadre, como el barranco de fondo plano al norte de Sariñena, o en el mismo nivel de la T III, tal como ocurre en el Saso de Albalatillo; y en otros casos alcanzar el Flúmen a través de los barrancos que por su orilla izquierda penetran en cuña en el nivel 
fundamental. Estas fluencias superficiales presentan direcciones diversas en las áreas depresivas receptoras, pero la dominante es norte-sur según la pendiente general del plano topográfico, aunque se producen divergencias finales hacia el suroeste y sureste.

El arroyamiento superficial que vierte hacia la cubeta lacustre es muy reducido, destacando solo el mencionado barranco de Saso Verde. Pero a pesar de su poca importancia habría que citar en esa misma margen septentrional las aguas de escorrentía que llegan a través de dos pequeñas vales al oeste del harranco, y las que estacionalmente fluyen por cauces indecisos y anastomosados en el mismo sector. Las aguas que superficialmente alimentan la laguna por las restantes márgenes son escasas y se reducen a las que pueden encauzarse a través de un pequeño barranco de fondo plano, muy retocado antrópicamente, al sureste de Sariñena; las que llegan a la laguna a través de un barranco de menos de un kilómetro de longitud y sin cauce fijo en la margen occidental; y finalmente las aguas de arroyada difusa en los momentos de lluvias.

A partir de manantiales la laguna se alimenta fundamentalmente por su margen nororiental, en cuya vertiente aparecen algunas resurgencias en el contacto entre las margas impermeables del talud y el nivel detrítico de cumbre. Los acuíferos reciben las aguas infiltradas a través del nivel cuaternario permeable, procedentes tanto de la precipitación como de los regadíos, habiéndose elevado notablemente el porcentaje de participación de estos últimos durante las décadas recientes.

\section{CONCLUSION}

La laguna de Sariñena sintetiza en el paisaje regional la convergencia de una serie de hechos de orden climático y topográfico-geológico que hán condicionado su génesis y pervivencia. Independientemente de su extensión y carácter permanente que le hacen acreedores de la importancia que posee desde el punto de vista geográfico y biológico, la gran originalidad de la laguna radica en su localización en una cubeta colgada sobre dos cursos de agua muy próximos, y cuya ineficacia erosiva sobre el soporte interfluvial de la laguna ha impedido la desaparición de ésta por captura, salvaguardándose asî üno de los ejemplos más sobresalientes no solo del endorreismo aragonés sino del conjunto de la Depresión del Ebro. 


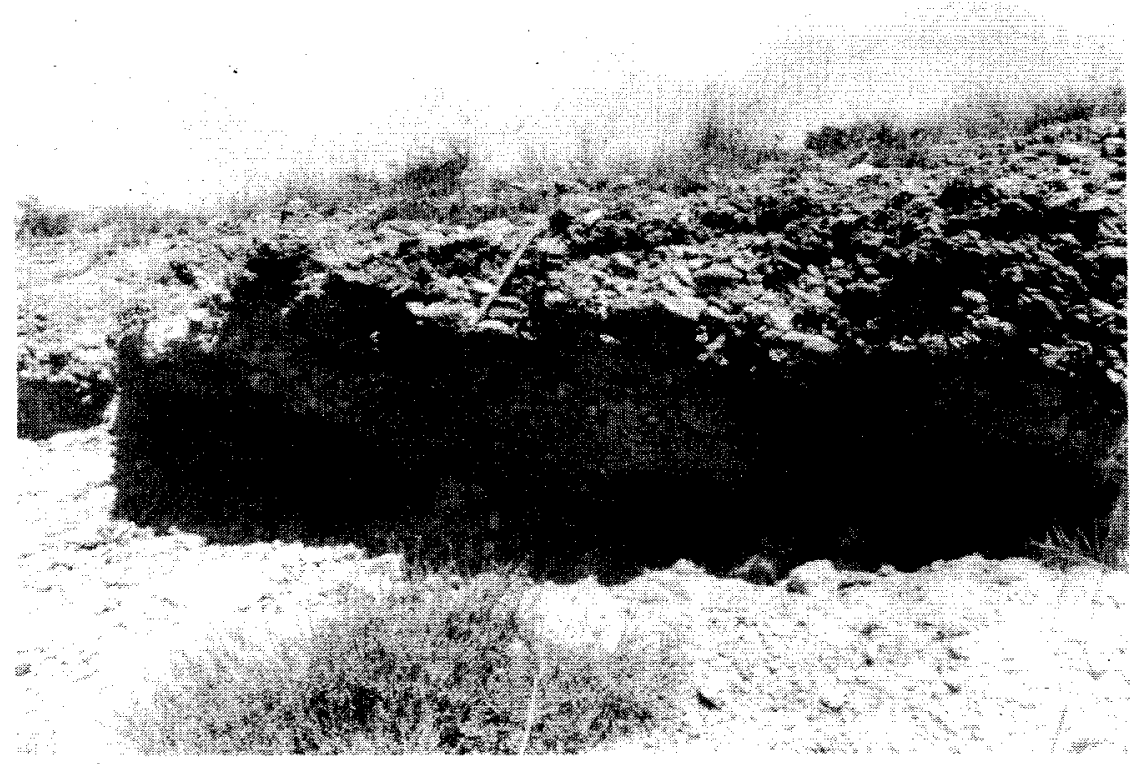

Fotografía 1.

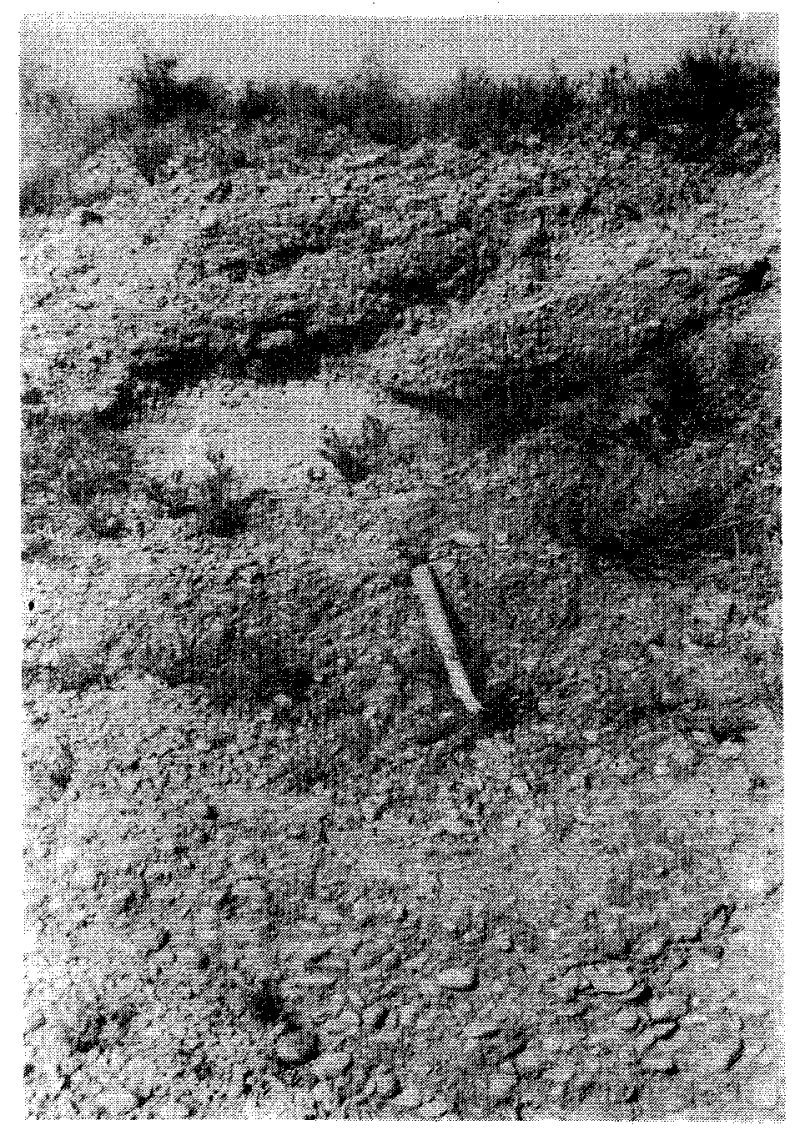

Fotografía 2. 


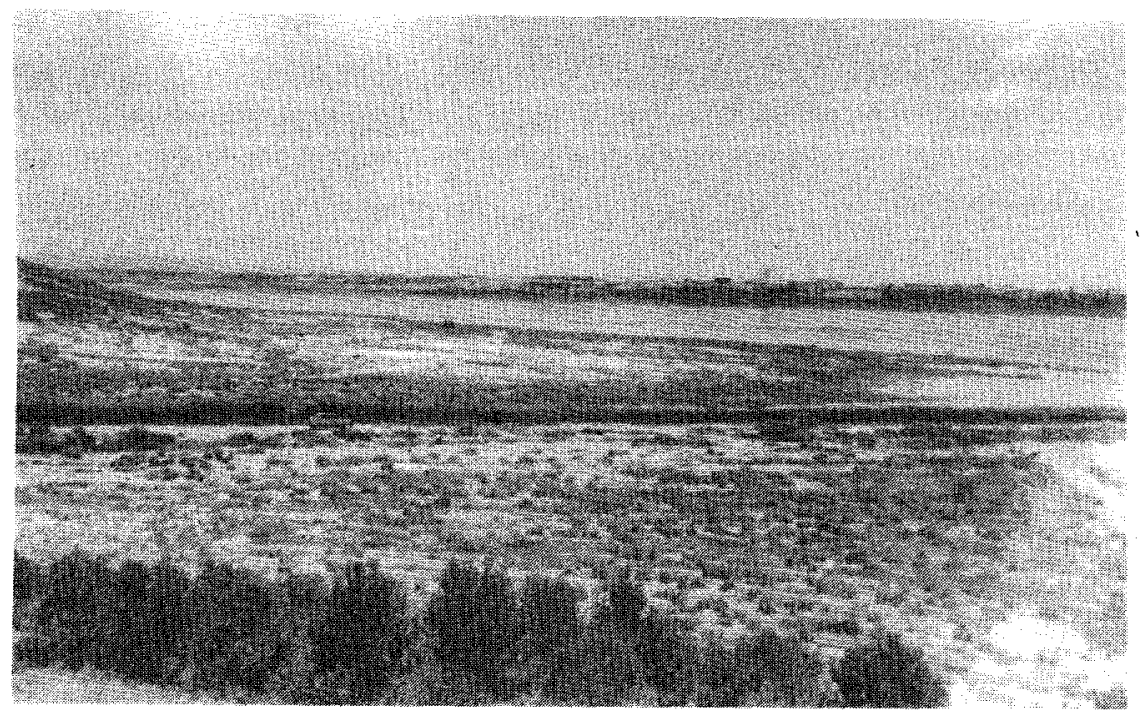

Fotografía 3.

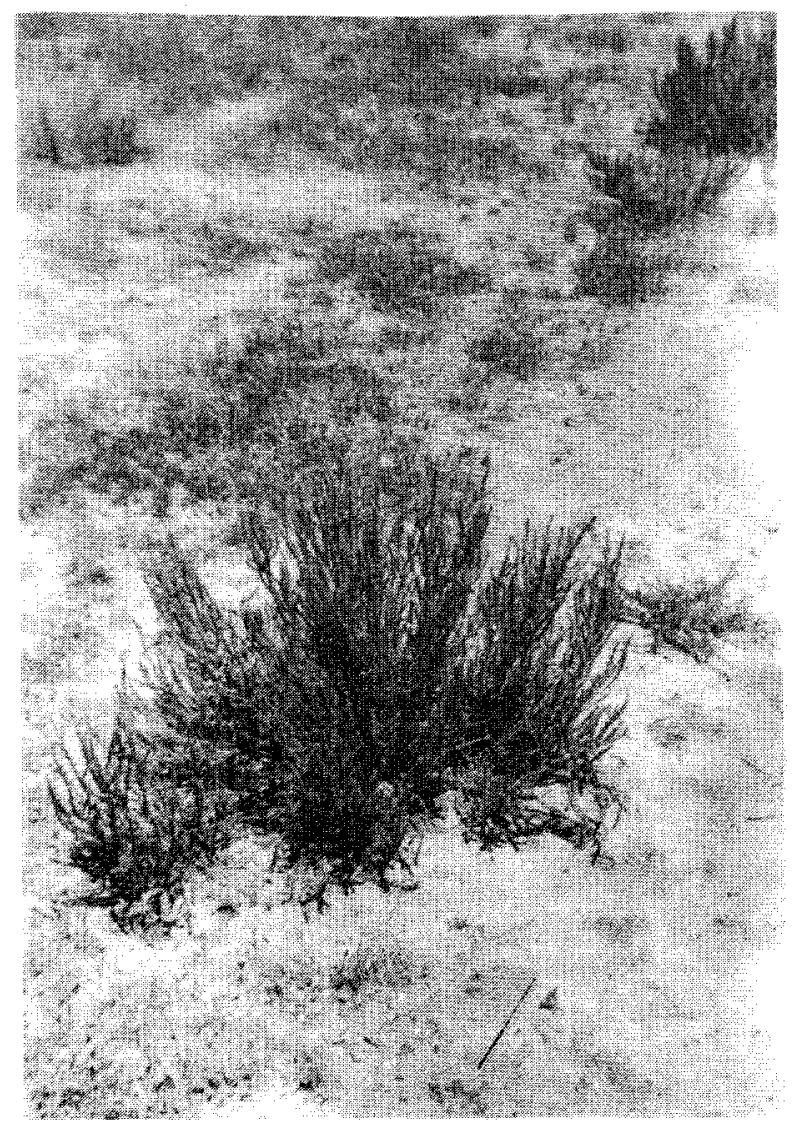

Fotografía 4. 


\section{BIBLIOGRAFIA}

Dantín Cereceda, J. (1942): "Distribución y extensión del endorreismo aragonés". Estudios Geográficos. Núm. 8, pp. 505-595.

IbÁñez, M. J. (1975): "El endorreismo del sector central de la Depresión del Ebro". Cuadernos de Investigación. Núm. 1, pp. 35-48.

Liso, M. y Ascaso, A. (1969): "Introducción al estudio de la evapotranspiración y clasificación climática de la cuenca del Ebro". Anales de la Estación Experimental del Aula Dei. Vol. 10, número 1-2.

Mensua, S. e IbÁñez, M. J. (1977): "Terrazas y glacis del centro de la Depresión del Ebro". III Reunión Nal. del G.E.T.C. Zaragoza.

QuiRanTES, J. (1965); “Nota sobre las lagunas de Bujaraloz-Sástago". Geographica. EneroDiciembre, pp. 31-39.

Quirantes, J. (1978): "Estudio sedimentológico y estratigráfico del Terciario continental de Los Monegros". C.S.I.C. Institución Fernando el Católico. Zaragoza. 